DR. TATIANA COBO-IBÁÑEZ (Orcid ID : 0000-0002-9220-1867)

DR. ANTONIO FERNANDEZ-NEBRO (Orcid ID : 0000-0002-2962-9844)

DR. JAVIER NARVÁEZ (Orcid ID : 0000-0002-1614-8064)

DR. CARLOS MONTILLA (Orcid ID : 0000-0003-2258-2868)

Article type : Original Article

\title{
RUNNING HEAD: Hormonal dependence and cancer in Systemic Lupus Erythematosus
}

\section{ARTICLE TITLE: Hormonal dependence and cancer in Systemic Lupus Erythematosus}

\section{Article type: Original article}

Authors: Tatiana Cobo-Ibáñez, $\mathrm{MD} \mathrm{PhD}^{1}$ *; Ana Urruticoechea-Arana, MD PhD²; Iñigo RúaFigueroa, MD PhD³; María A Martín-Martínez, MD; Juan Gabriel Ovalles-Bonilla, MD PhD; María Galindo, $\mathrm{MD} \mathrm{PhD}^{6}$; Jaime Calvo-Alén $\mathrm{MD} \mathrm{PhD}^{7}$; Alejandro Olivé, $\mathrm{MD} \mathrm{PhD}^{8}$; Antonio Fernández-Nebro, MD PhD9; Raúl Menor-Almagro , MD ${ }^{10}$; Eva Tomero ,MD ${ }^{11}$; Loreto Horcada, MD 12; Esther Uriarte-Itzazelaia, MD ${ }^{13}$; Víctor M Martínez- Taboada, MD PhD ${ }^{14}$; José Luis Andreu, MD PhD ${ }^{15}$; Alina Boteanu, MD ${ }^{16}$; Javier Narváez, MD PhD ${ }^{17}$; Cristina Bohorquez, MD ${ }^{18}$; Carlos Montilla, MD PhD ${ }^{19}$; Gregorio Santos, MD²0; Blanca Hernández-Cruz, MD PhD²1; Paloma Vela, MD $\mathrm{PhD}^{22}$; Eva Salgado, MD PhD ${ }^{23}$; Mercedes Freire, MD²4; José Ángel Hernández-Beriain, MD PhD²5; Elvira Díez-Álvarez ,MD²6; Lorena Expósito, $\mathrm{MD}^{27}$; Olaia Fernández-Berrizbeitia, MD PhD²8; María Luisa Velloso-Feijoo, MD29; Mónica Ibáñez-Barceló, MD³0; Nuria Lozano-Rivas, MD¹; Gema Bonilla, MD²; Mireia Moreno, MD³; Enrique Raya, MD³; Víctor Eliseo Quevedo-Vila, MD ${ }^{35}$; Tomas Ramón Vázquez-Rodríguez, MD³6; Jesús Ibáñez-Ruan, MD³7; Santiago Muñoz-Fernández,

This article has been accepted for publication and undergone full peer review but has not been through the copyediting, typesetting, pagination and proofreading process, which may lead to differences between this version and the Version of Record. Please cite this article as doi: 10.1002/acr.24068

This article is protected by copyright. All rights reserved 
MD PhD¹; Fernando Sánchez-Alonso, MD MSc4; José María Pego-Reigosa, MD PhD ${ }^{38}$.

${ }^{1}$ Rheumatology Department. Hospital Universitario Infanta Sofía, Universidad Europea, Madrid, Spain.

${ }^{2}$ Rheumatology Department. Hospital Can Misses, Ibiza, Spain.

${ }^{3}$ Rheumatology Department. Hospital Universitario Doctor Negrín, Gran Canaria, Spain.

${ }^{4}$ Research Unit, Sociedad Española de Reumatología, Madrid, Spain.

${ }^{5}$ Rheumatology Department. Hospital Universitario Gregorio Marañón, Madrid, Spain.

${ }^{6}$ Rheumatology Department. Hospital Universitario 12 de Octubre, Madrid, Spain.

${ }^{7}$ Rheumatology Department. Hospital Universitario Araba, Universidad del País Vasco, Vitoria, Spain.

${ }^{8}$ Rheumatology Department. Hospital Universitario Germans Trias i Pujol, Barcelona, Spain.

${ }^{9}$ Rheumatology Department. Instituto de Investigación Biomédica de Málaga (IBIMA), Hospital Universitario Regional de Málaga, Universidad de Málaga, Málaga, Spain.

${ }^{10}$ Rheumatology Department. Hospital Universitario de Jerez, Cádiz, Spain.

${ }^{11}$ Rheumatology Department. Hospital Universitario de la Princesa, Madrid, Spain.

${ }^{12}$ Rheumatology Department. Complejo Hospitalario de Navarra, Pamplona, Spain.

${ }^{13}$ Rheumatology Department. Hospital Universitario de Donostia, Guipuzcua, Spain.

${ }^{14}$ Rheumatology Department. Hospital Universitario Marqués de Valdecilla, Universidad de Cantabria, Santander, Spain.

${ }^{15}$ Rheumatology Department. Hospital Universitario Puerta de Hierro-Majadahonda, Madrid, Spain.

${ }^{16}$ Rheumatology Department. Hospital Universitario Ramón y Cajal, Madrid, Spain. 
${ }^{17}$ Rheumatology Department. Hospital Universitario de Bellvitge, Barcelona, Spain.

${ }^{18}$ Rheumatology Department. Hospital Universitario Príncipe de Asturias, Madrid, Spain.

${ }^{19}$ Rheumatology Department. Hospital Universitario de Salamanca, Salamanca, Spain.

${ }^{20}$ Rheumatology Department. Hospital Marina Baixa, Alicante, Spain.

${ }^{21}$ Rheumatology Department. Hospital Universitario Virgen Macarena, Sevilla, Spain.

${ }^{22}$ Rheumatology Department. Hospital General Universitario Alicante, Universidad Miguel Hernández, Alicante, Spain.

${ }^{23}$ Rheumatology Department. Complejo Hospitalario Universitario de Orense, Orense, Spain.

${ }^{24}$ Rheumatology Department. Complejo Hospitalario Universitario A Coruña , A Coruña, Spain.

${ }^{25}$ Rheumatology Department. Hospital Universitario Insular de Gran Canaria, Las Palmas de Gran Canaria, Spain.

${ }^{26}$ Rheumatology Department. Hospital Universitario de León, León. Spain.

${ }^{27}$ Rheumatology Department. Hospital Universitario Clínico de Tenerife, Tenerife, Spain.

${ }^{28}$ Rheumatology Department. Hospital Universitario Basurto, Basurto, Spain.

${ }^{29}$ Rheumatology Department. Hospital Universitario Valme, Sevilla, Spain.

${ }^{30}$ Rheumatology Department. Hospital Son Llatzer, Palma de Mallorca, Spain.

${ }^{31}$ Rheumatology Department. Hospital Universitario Virgen de la Arrixaca, Murcia, Spain.

${ }^{32}$ Rheumatology Department. Hospital Universitario la Paz, Madrid, Spain.

${ }^{33}$ Rheumatology Department. Hospital Parc Tauli, Barcelona, Spain.

${ }^{34}$ Rheumatology Department. Hospital Universitario San Cecilio, Granada, Spain.

${ }^{35}$ Rheumatology Department. Hospital Comarcal de Monforte de Lemos, Lugo, Spain.

This article is protected by copyright. All rights reserved 
${ }^{36}$ Rheumatology Department. Hospital Universitario Lucus Augusti, Lugo, Spain.

${ }^{37}$ Rheumatology Department. Hospital Povisa, Vigo, Spain.

${ }^{38}$ Rheumatology Department. Complejo Hospitalario Universitario de Vigo, Instituto de Investigación Biomédica de Vigo, Vigo, Spain.

*Corresponding author: Tatiana Cobo-Ibáñez, MD PhD. Rheumatology Department. Hospital Universitario Infanta Sofía. Paseo de Europa 34, 28702 San Sebastián de los Reyes, Madrid, Spain.

email: mtcoboiba@yahoo.es; Phone: + 34 911914037. Fax: +34 911915390

Word Count: 3033.

Funding: The RELESSER Registry was partially funded by GSK, Roche, UCB, Lilly and Novartis. The sponsors had no role in the study design, data collection, analysis or interpretation, in writing the report, or in the decision to submit the article for publication. Dr. Pego-Reigosa is supported by grant 316265 (BIOCAPS) from the European Union $7^{\text {th }}$ Framework Program (FP7/REGPOT-20122013.1). The FIS Grant PI11/02857 (Instituto Carlos III, Fondos FEDER) supported this study.

Disclosure Statement: The authors declare no conflicts of interest regarding this study. 


\section{ABSTRACT}

Objective: To estimate the incidence and analyze any cancer-associated factors in patients with Systemic Lupus Erythematosus (SLE) differentiating between hormone-sensitive (HS) and non-HS cancers.

Methods: Retrospective multicentric study of a patient cohort from the SLE Registry of the Spanish Society of Rheumatology (RELESSER - Spanish acronym). Included are the following: the first cancer post-SLE diagnosis, clinical and sociodemographic information, cumulative damage, severity, comorbidities, treatments and refractoriness. Cancers were classified as HS (prostate, breast, endometrium and ovarian) and non-HS (the rest). Standardized Incidence Ratio (SIR) was calculated and logistic regression models were built.

Results: 3,539 patients (90.4\% women) were included, 154 of whom presented cancer (91\% women), $44 \mathrm{HS}$ (100\% women). Cancer SIR was 1.37 (CI 95\%: 1.15-1.59), with higher values in women under 65s [2.38 (CI 95\%: 1.84-2.91)]. SIR in women with HS vs. non-HS cancer was 1.02 (Cl 95\%: 0.13-1.91) and 1.93 (Cl 95\%: 0.98-2.89)], respectively. In HS vs. non-HS cancers, SLE diagnostic age [odds ratio (OR) $1.04(p=0.002)$ vs. $1.04(p=0.019)$, respectively] and period of disease evolution [OR $1.01(p<0.001)$ vs. $1.00(p=0.029)$, respectively] were associated with cancer. SLICC/ACR damage index [OR $1.27(p=0.022)]$ and ACE inhibitor prescriptions [OR 2.87 $(p=0.048)]$ were associated with non-HS cancers. 
Conclusion: Cancer incidence in SLE patients is higher than in the Spanish population, particularly among young women. This increase might be due to non-HS cancers, which would be associated with an SLE involving greater cumulative damage where more ACE inhibitors are prescribed.

Keywords: systemic lupus erythematosus, cancer, incidence, hormone-sensitive

SIGNIFICANCE AND INNOVATIONS

- Cancer incidence rate in SLE patients is estimated to be higher with regard to the Spanish population.

This article is protected by copyright. All rights reserved 
- Cancer risk was higher in women under 65 and those with non-HS cancers.

- SLE diagnostic age and period of disease evolution were common factors associated with both HS and non-HS cancers.

- ACE inhibitor prescriptions and the greater cumulative damage were also associated with non-HS cancers.

Cancer is one of the most serious illnesses a person can have, as it affects both the physical and emotional state and can sometimes lead to death. Furthermore, when cancer is diagnosed in a patient with a chronic autoimmune disease such as systemic lupus erythematosus (SLE), with its associated cumulative damage and comorbidities, it presents challenges not only for that patient, but also for the doctors assessing and treating both illnesses. At present, there is insufficient knowledge regarding the immune system alterations that occur in SLE, changes which may influence cancer onset and/or development (1). Several studies carried out in different countries, races and ethnic groups show that the global cancer incidence in SLE patients is higher than in 
the general population (2-7). In particular, the cancer standardized incidence ratio (SIR) is higher across virtually all anatomic locations (hematological, lung, thyroid, hepatobiliary, vulva-vagina, cervix, and pancreas) $(2,3,5,6,8,9)$. However, different studies have also highlighted a risk reduction in hormone-sensitive (HS) cancers such as breast, endometrial and ovarian (2-4, 10, 11). It has been suggested that if the metabolism of estrogen or other predominantly female hormones was altered in SLE, it could slow the progression of hormone-sensitive cancers. On the other hand, a nucleolytic lupus autoantibody, anti-5C6, might help prevent DNA repair mechanisms in breast, ovarian, and prostate cancers associated with BRCA2 mutations (12). Therefore it is possible that SLE autoantibodies may contribute to a decreased risk of certain hormone-sensitive cancers. Thus, it appears that in patients with SLE there might exist some differences in the cancers vis-à-vis hormonal dependence, although the exact mechanisms linking the immune and endocrine systems to cancer risk are unknown. For this reason, it would be interesting to determine whether factors associated with HS cancer differ from those with nonHS. Most studies have focused on searching for factors associated with cancer onset in SLE and have grouped all cancer types, whereas others have explored factors related to the onset of hematological, lung and breast cancer. Yet to date no study has explored stratified cancers vis-àvis hormone-sensitivity. Thus, an analysis comparing HS and non-HS cancers within a multicentric cohort with a large number of patients might expand our understanding in this sense.

The purpose of this study was to estimate the cancer incidence in SLE patients and to analyze factors associated with its onset, differentiating between HS and non-HS cancers.

\section{PATIENTS AND METHODS}

\section{Design, scope and participants}

A retrospective observational longitudinal study of a cohort of RELESSER registry patients.

Participants. RELESSER includes patients over 16 years of age with SLE (per the revised American College Rheumatology (ACR) criteria of 1997) (13) from 45 hospitals registered with the Spanish Society of Rheumatology (SER) hospital database. At least $80 \%$ of patients from each centre were included, all of whom having had at least one appointment with a rheumatology department at some time since their initial disease diagnosis. Patients whose clinical history did not contain at 
least $50 \%$ of the information deemed essential were excluded. The design, variables, and general characteristics of the RELESSER registry have been published previously (14).

\section{Data collection}

Rheumatologists with experience in diagnosing and treating SLE patients collected the data from each centre, and then uploaded it via an online software application designed ad hoc for the project. Data quality control was performed via professional online monitoring.

\section{Variables and operational definitions}

The main study variable was the first cancer after SLE diagnosis. Endometrial, breast, ovarian and prostate cancers were classified HS and the rest non-HS. Patient follow-up was defined as the period between the date of SLE diagnosis and the date of the first cancer for those presenting the study event, and the RELESSER data collection date (2010-2011) for patients who did not develop cancer. Patients for whom information was unavailable until the data collection date were censored to the date of their last appointment at the rheumatology surgery. Secondary variables included: 1) sociodemographic; 2) general symptoms; 3) cancer location; 4) accumulated SLE symptoms, defined per ACR diagnostic criteria $(13,15)$ and BILAG definitions (16); 5) SLEDAI (Systemic Lupus Erythematosus Disease Activity Index) activity $(17,18)$; 6) damage per the SLICC/ACR DI (Systemic Lupus International Collaborative Clinics/American College of Rheumatology Damage Index) (19), excluding cancer; 7) degree of severity (Katz index) (20); 8) comorbidities, hospitalizations and causes of death; 9) Charlson comorbidity index, Deyo modified version $(21)$; 10) treatments for comorbidities and SLE control; and 11) refractoriness, as defined for the registry (22).

\section{Statistical analysis}

A descriptive analysis was performed using absolute and relative frequencies of qualitative variables, mean or median and dispersion measures (SD: standard deviation, IR: interquartile range) for quantitative variables. The accumulated incidence (Al) of cancers in patients included in RELESSER for 2011 was calculated. To estimate cancer Al in the general population, cancer cases in Spain for 2012 were compiled and measured against the overall population per the 2011 Housing \& Population Census $(23,24)$. Both Al measures were compared by calculating the standardized incidence ration (SIR). The latter was determined at the same time, differentiating between HS and non-HS cancers, and taking into account the number of cases per cancer type in 
Spain during 2014 (25). In addition, the prevalence of cancer globally and per anatomic location was estimated. The years between the diagnosis of SLE and the development of the first cancer were also calculated, as well as the mortality rate for each cancer type according to anatomical location. With a view to analyzing the association between cancer onset and the clinical characteristics of SLE patients, a logistics regression model was built to analyze female patients, differentiating between HS and non-HS cancer. The Odds Ratio (OR) was calculated for all independent variables together with their confidence value $(\mathrm{Cl})$ at $95 \%$. Inclusion of independent variables in a multivariant model was based on clinical judgment and a $p$-value $<0.25$ obtained in the bivariant analysis. The absence of multi-co-linearity among independent variables included was checked with the Kappa correlation coefficients in the case of qualitative variables, and with the Pearson correlation for quantitative variables. In the final logistic regression model, the independent variables were adjusted by all the other model variables.

Ethical aspects: This project complied with principles of the Helsinki Declaration (26). The project also received the approval of the general Clinical Research Ethics Committee (CREC) (Doctor Negrín University Hospital of Gran Canaria), as well as the approval of the CREC at each centre where required.

\section{RESULTS}

\section{Participants}

The total number of patients included in the analysis were 3,539, $90.4 \%$ of whom were women with a mean age at diagnosis of 35 and a mean period of disease evolution of 143 months (Table 1). The main characteristics of the registry patients have been published previously (14).

\section{Patient characteristics according to cancer presence}

The main characteristics of patients with a first cancer onset since SLE diagnosis compared to those without are detailed in Table 1. The total number of patients with cancer was 154 (4.35\%), $91 \%$ of whom were women, with a mean diagnostic age of 40.37 (SD 15.7) years. Age at diagnosis, the period of disease evolution, Sjögren Syndrome (SS) association, KATZ, SLICC/ACR and Charlson indexes, and the prescription of statins was higher in patients with cancer. 
However, the SLEDAI and number of hospitalizations due to SLE activity were higher in patients without cancer.

\section{Patient characteristics per HS and non-HS cancers}

Out of the 154 patients with cancer, only 14 presented in men and none were hormone dependent. Table 2 shows the HS and non-HS cancer characteristics in women. Both the SLICC/ACR and Charlson indexes had higher values in patients with non-HS cancers.

\section{Cancer incidence}

Cancer Al in SLE patients was 6.31 cases per 1000 patients (Cl 95\%: 4.00-9.45). After stratifying by age and gender, the group with the highest number of first cancers (16 cases per 1000 patients (CI 95\%: 6.45-32.65)) was that of women over 64 (Table 3). Cancer SIR was 1.37 (CI 95\%: 1.151.59) and the group with the highest values was that of women under 65 , with $2.38(\mathrm{Cl} 95 \%$ : 1.84-2.91) (Table 4). In women, HS cancer SIR was 1.02 (Cl 95\%: 0.13-1.91) and for non-HS patients it was 1.93 (Cl 95\%: 0.98-2.89).

\section{Cancer prevalence and distribution}

As to the distribution of cancer according to anatomic location, breast and gynecological cancer were the most frequently recorded ( $23.4 \%$ and $20.1 \%$, respectively), followed by hematological (75\% non-Hodgkin lymphoma (NHL) and 25\% Hodgkin lymphoma) and skin (non-melanoma), both $11.7 \%$. These were followed by colorectal and thyroid cancer (both $5.2 \%$ ), lung cancer (3.25\%), and other locations (19.5\%). After analyzing the subgroup of SLE patients with associated SS, the most frequent location was breast cancer at $29 \%$, followed by gynecological and hematological, both at $16.1 \%$. NHL was the most common hematological cancer $(60 \%)$ in SLE patients with associated SS.

\section{Time frame for cancer onset}

The median time frame until the onset of the first cancer was 10 years (IR: 5.75-17.00), which was significantly shorter in women [9.5 (IR: 5.00-17.0) years] than in men [12.5 (IR: 8.75-17.5) 
years], and in patients under 45 [8.0 (IR: 5.00-16.00) years] versus over 45 [10.9 (IR: 7.0-18.6 years)].

\section{Death due to cancer}

Global mortality was $5.5 \%$ of patients, with cancer being the fourth leading cause of death, after SLE itself, cardiovascular disease and infections. Death due to cancer in patients included in the study was $10.66 \%$, with the most prevalent being hematological (19\%) and breast (19\%) cancers, followed by lung (14.3\%) and colorectal (9.5\%).

\section{Factors associated with cancer onset in women}

Tables 5 and 6 show the results obtained in the bivariant analysis of HS and non-HS cancers. Regarding the multivariant model, the variables presenting significant associations with HS cancer onset were SLE diagnostic age (OR 1.4; CI 95\%: 1.01-1.07; $p=0.002$ ) and period of disease evolution (OR 1.01; $\mathrm{Cl} 95 \%$ : 1.00-1.01; $\mathrm{p}<0.001$ ). The multivariate model of non-HS cancers showed a significant association with SLE diagnostic age (OR 1.04; Cl 95\%: 1.01-1.07; p=0.019), evolution period (OR 1.00; Cl 95\%: 1.00-1.01; $p=0.029$ ), SLICC/ACR DI (OR 1.27; CI 95\%: 1.041.57; $\mathrm{p}=0.022$ ) and prescription of angiotensin-converting enzyme (ACE) inhibitors (OR 2.87; $\mathrm{Cl}$ 95\%: 1.01-8.14; $p=0.048$ ) (Tables 5 and 6).

\section{DISCUSSION}

The results obtained in this national retrospective multicentric study showed that the cancer incidence in SLE patients is higher than in the general population, with said differences being more striking in women under 65, and those with non-HS cancers. Furthermore, breast, gynecological and hematological cancers were the most frequently recorded in SLE patients and those with associated SS. Onset of the first cancer post-SLE diagnosis occurred around 10 years later, with breast and hematological cancers causing more deaths. Both SLE diagnostic age and the period of disease evolution were factors associated with HS and non-HS cancers. However, SLICC/ACR DI and ACE inhibitor prescriptions were solely associated with non-HS cancers. 
The differences found among patients with and without cancer on the Katz and Charlson indexes, as well as a statin prescription, suggest that cancer patients have a more serious clinical state and greater risk of comorbidities. These variables had not been analyzed in previous studies, although the SLICC/ACR DI had, the latter showing higher values in patients with cancer (27), results consistent with our own study. As to the number of hospitalizations per SLE activity, we noted a paradox; i.e., patients without cancer were hospitalized more frequently. This might be due to the effect of oncological drugs on the activity and evolution of SLE.

On analyzing the differences between women with HS or non-HS cancers, our study revealed that the damage associated with SLE and comorbidity was higher only in patients with non-HS cancers. Notwithstanding such evidence, these results have yet to be replicated by other groups. Nonetheless, we consider this a relevant finding since patients with non-HS cancers might require a more complex clinical and therapeutic approach.

Several studies in different countries, races and ethnic groups have noted a global cancer increase with an SIR between 1.14 and 3.6 (1). Likewise, those studies that stratified SIR by gender and age found this increase particularly prevalent in women between 21 and 64 years of age $(2,28)$. In our Spanish cohort, the results support previously published findings. Regarding HS breast, endometrial and ovarian cancers, a very slight and not significant increase has been suggested $(29,30)$; likewise, a significant drop in $\operatorname{SIR}$ has been observed $(2,3,6,10,11)$. This has led to the belief that a direct association cannot be established between SLE and the risk of HS cancers. Our study detected a very slight, albeit not significant, increase in SIR in women with HS cancers. In non-HS cancers, the increase was higher although it remained at the limit of statistical significance.

Regarding distribution by location, breast, gynecological and hematological (especially NHL) cancers were the most prevalent. These three cancers were also among the most frequent in other cohorts, which was true of studies carried out on different races or ethnic groups $(2-4,28$, 30). In fact, this distribution was maintained in SLE and SS patients, with the hematological tumor NHL being the most frequently recorded, as is the case with primary SS (28).

This article is protected by copyright. All rights reserved 
Focusing on the time frame relationship between SLE and cancer, our patients developed cancer post-SLE diagnosis within a median of 10 years (9 years in women under 45 ). Other authors have tackled this time frame relationship via cancer risk stratification (SIR) pursuant to follow-up time. They found an increased global cancer risk between under one year and over 8 years from the time of SLE diagnosis, with a greater risk during the first year of follow-up $(2,4,28)$.

Among the Spanish population, the cancers most frequently causing death in men are lung, colorectal and prostate, while in women they are breast, colorectal and lung $(24,25)$. In our essentially female cohort, the same distribution held true, though hematological cancers also met first-line inclusion. This is not surprising given that chronic immune deregulation due to SLE is associated with greater lymphoid proliferation, thus increasing the risk of hematological tumors, specifically NHL(31).

We are aware that the global standardized mortality rate for cancer in SLE has not increased (32). Patients with chronic diseases are subject to greater vigilance, which may favor early cancer diagnosis and improved prognosis. It has also been suggested that SLE patients present a competitive premature mortality due to other causes like cardiovascular disease, infections, and lupus nephritis (32). Our results support this suggestion, since cancer was the fourth leading cause of death after SLE itself, cardiovascular disease and infections.

SLE diagnostic age and period of disease evolution were associated with both HS and non-HS cancers. In other studies, age was associated with cancer in general, in particular breast cancer and lymphomas $(27,33,34)$. Bernasky et al. have suggested that lupus duration confers a protective effect against cancer onset (27). This potentially contradicts our results, although their study had a different design and SLE duration was established from the time the patient was included in the cohort, as opposed to the time of SLE diagnosis as in our study. Accumulated SLE damage and ACE inhibitor prescriptions were solely associated with non-HS cancers. The SLICC/ACR DI was found to be a possible factor associated with cancer (27); however, until now it was not known that this association is an underlying factor in non-HS cancers. We have no information regarding ACE inhibitor prescriptions as a cancer-associated factor in SLE, since it had not been included in previous analyses. In our cohort, those patients with cancer who had been prescribed ACE inhibitors suffered hypertension and lupus nephritis with greater frequency 
than those without ACE inhibitors. The role ACE inhibitors might play in cancer risk is highly controversial, not only in SLE but in the general population as well. While some studies suggest they may increase the risk of certain cancers, such as in the lung (35), others show a reduction or absence of such an association

We found no association between HS cancers and oral contraception, the number of pregnancies or menopause, nor has this association been previously demonstrated with breast cancer (33).

Our results provide evidence that there are several factors exclusively associated with non-HS cancers. This would support the hypothesis that there are differences in cancer according to hormonal dependence. If these differences are confirmed by subsequent studies, the way patients are assessed will also likely change. Preventative measures and/or cancer screening in patients with SLE based on the risk associated with hormonal dependence may be adopted.

Our study has several limitations. Its retrospective design might render the results somewhat less reliable. Nevertheless, it remains an acceptable design for tackling infrequent events like cancer. The increased risk of non-HS cancers was on the threshold of significance, for although the total number of cancers was not depreciable when the SIRs of HS and non-HS cancers were separated, statistical power was nonetheless lost. The variables included in our model better explain the non-HS cancers, which leads us to believe that there are still other variables requiring identification and which are associated with HS cancers.

One of the strengths of this study is that it is the largest SLE multicentric cohort published in Europe. In addition, we included variables not previously analyzed in other studies. Moreover, as the data were drawn from a clinical registry, as opposed to an administrative national health insurance database, we had more detailed information on the disease, allowing us to better adjust the models. Finally, the comparison between HS and non-HS cancers had not been explored before; as such, it has greatly expanded upon information previously only hypothesized regarding the differences among these cancer types.

In conclusion, the cancer incidence in SLE patients is higher than in the general Spanish population, particularly in young women. Above all, the incidence rate may be dependent on non-HS cancers. SLE age at diagnosis and period of disease evolution were common factors 
associated with both HS and non-HS cancers. However, non-HS cancers were also associated with ACE inhibitor prescriptions and greater accumulated damage. Further studies confirming our findings on the differences between HS and non-HS cancer are greatly warranted, as is a renewed search for factors that most clearly determine the risk of such cancers.

\section{AUTHOR CONTRIBUTION:}

All authors who made substantial contributions to data collection were not only involved in drafting the article and/or revising it critically for intellectual content, but also approved the final version for submission. Dr. Martín-Martínez had full access to all of the data in the study and takes responsibility for the integrity of the data and the accuracy of the data analysis.

Study conception and design: Cobo-Ibáñez, Urrucoechea-Arana, Rúa-Figueroa and MartínMartínez.

Data collection: all authors.

Analysis and interpretation of data: Cobo-lbáñez, Martín-Martínez, Rúa-Figueroa. 


\section{REFERENCES}

1. Choi MY, Flood K, Bernatsky S, Ramsey-Goldman R, Clarke AE. A review on SLE and malignancy. Best practice \& research Clinical rheumatology. 2017;31(3):373-96.

2. Bernatsky S, Ramsey-Goldman R, Labrecque J, Joseph L, Boivin JF, Petri M, et al. Cancer risk in systemic lupus: an updated international multi-centre cohort study. Journal of autoimmunity. 2013;42:130-5.

3. Parikh-Patel A, White RH, Allen M, Cress R. Cancer risk in a cohort of patients with systemic lupus erythematosus (SLE) in California. Cancer causes \& control : CCC. 2008;19(8):887-94.

4. Chen YJ, Chang YT, Wang CB, Wu CY. Malignancy in systemic lupus erythematosus: a nationwide cohort study in Taiwan. The American journal of medicine. 2010;123(12):1150.e1-6.

5. Cao L, Tong H, Xu G, Liu P, Meng H, Wang J, et al. Systemic lupus erythematous and malignancy risk: a meta-analysis. PloS one. 2015;10(4):e0122964.

6. Mao S, Shen H, Zhang J. Systemic lupus erythematosus and malignancies risk. Journal of cancer research and clinical oncology. 2016;142(1):253-62.

7. Hidalgo-Conde A, de Haro Liger M, Abarca-Costalago M, Alvarez Perez M, Valdivielso-Felices P, Gonzalez-Santos P, et al. Incidence of cancer in a cohort of Spanish patients with systemic lupus erythematosus. Reumatologia clinica. 2013;9(6):359-64.

8. $\mathrm{Ni}$ J, Qiu LJ, Hu LF, Cen H, Zhang M, Wen PF, et al. Lung, liver, prostate, bladder malignancies risk in systemic lupus erythematosus: evidence from a meta-analysis. Lupus. 2014;23(3):284-92.

9. Apor E, O'Brien J, Stephen M, Castillo JJ. Systemic lupus erythematosus is associated with increased incidence of hematologic malignancies: a meta-analysis of prospective cohort studies. Leukemia research. 2014;38(9):1067-71.

This article is protected by copyright. All rights reserved 
10. Bernatsky S, Ramsey-Goldman R, Foulkes WD, Gordon C, Clarke AE. Breast, ovarian, and endometrial malignancies in systemic lupus erythematosus: a meta-analysis. British journal of cancer. 2011;104(9):1478-81.

11. Dey D, Kenu E, Isenberg DA. Cancer complicating systemic lupus erythematosus--a dichotomy emerging from a nested case-control study. Lupus. 2013;22(9):919-27.

12. Noble PW, Young MR, Bernatsky S, Weisbart RH, Hansen JE. A nucleolytic lupus autoantibody is toxic to BRCA2-deficient cancer cells. Scientific reports. 2014; 4: 5958.

13. Hochberg MC. Updating the American College of Rheumatology revised criteria for the classification of systemic lupus erythematosus. Arthritis and rheumatism. 1997;40(9):1725.

14. Rua-Figueroa I, Lopez-Longo FJ, Calvo-Alen J, Galindo-Izquierdo M, Loza E, Garcia de Yebenes MJ, et al. National registry of patients with systemic lupus erythematosus of the Spanish Society of Rheumatology: objectives and methodology. Reumatologia clinica. 2014;10(1):17-24.

15. Tan EM, Cohen AS, Fries JF, Masi AT, McShane DJ, Rothfield NF, et al. The 1982 revised criteria for the classification of systemic lupus erythematosus. Arthritis and rheumatism. 1982;25(11):1271-7.

16. Yee CS, Farewell V, Isenberg DA, Prabu A, Sokoll K, Teh LS, et al. Revised British Isles Lupus Assessment Group 2004 index: a reliable tool for assessment of systemic lupus erythematosus activity. Arthritis and rheumatism. 2006;54(10):3300-5.

17. Hawker G, Gabriel S, Bombardier C, Goldsmith C, Caron D, Gladman D. A reliability study of SLEDAI: a disease activity index for systemic lupus erythematosus. The Journal of rheumatology. 1993;20(4):657-60.

18. Bencivelli W, Vitali C, Isenberg DA, Smolen JS, Snaith ML, Sciuto M, et al. Disease activity in systemic lupus erythematosus: report of the Consensus Study Group of the European Workshop for Rheumatology Research. III. Development of a computerised clinical chart and its application to the comparison of different indices of disease activity. The European Consensus Study Group for Disease Activity in SLE. Clinical and experimental rheumatology. 1992;10(5):549-54.

19. Gladman D, Ginzler E, Goldsmith C, Fortin P, Liang M, Urowitz M, et al. The development and initial validation of the Systemic Lupus International Collaborating Clinics/American College of Rheumatology damage index for systemic lupus erythematosus. Arthritis and rheumatism. 1996;39(3):363-9.

20. Katz JD, Senecal JL, Rivest C, Goulet JR, Rothfield N. A simple severity of disease index for systemic lupus erythematosus. Lupus. 1993;2(2):119-23.

21. Deyo RA, Cherkin DC, Ciol MA. Adapting a clinical comorbidity index for use with ICD-9-CM administrative databases. Journal of clinical epidemiology. 1992;45(6):613-9.

This article is protected by copyright. All rights reserved 
22. Pego-Reigosa JM, Rua-Figueroa I, Lopez-Longo FJ, Galindo-Izquierdo M, Calvo-Alen J, OliveMarques A, et al. Analysis of disease activity and response to treatment in a large Spanish cohort of patients with systemic lupus erythematosus. Lupus. 2015;24(7):720-9.

23. Censo de población y viviendas 2011. Resultados Nacionales, por Comunidades Autónomas y Provincias. Población por sexo, edad (grupos quinquenales) y relación entre el lugar de nacimiento y el de residencia [Internet]. Instituto Nacional de Estadística; (acceso 18 de julio de 2017). Disponible en: http://www.ine.es/jaxi/Tabla.htm?path=/t20/e244/avance/p01/10/\&file=03003.px\&L=0. [

24. López-Abente G NO, Pérez-Gómez B, Aragonés N, Pollán M. La situación del cáncer en España: Informe 2015. Madrid,2015.

25. Galceran J AA, Carulla M, Mateos A, Quirós JR, Alemán A, et al. Estimaciones de la Incidencia y la supervivencia del cáncer en España y su situación en Europa. Informe de la Red Española de Regisros de Cáncer (Redecan)Octubre 2014.

26. World Medical Association Declaration of Helsinki. Ethical Principles for Medical Research Involving Human Subjects [2013 version] Available in:

//www.wma.neten/20activities/10ethics/10helsinki. [

27. Bernatsky S, Joseph L, Boivin JF, Gordon C, Urowitz M, Gladman D, et al. The relationship between cancer and medication exposures in systemic lupus erythaematosus: a case-cohort study. Annals of the rheumatic diseases. 2008;67(1):74-9.

28. Yu KH, Kuo CF, Huang LH, Huang WK, See LC. Cancer Risk in Patients With Inflammatory Systemic Autoimmune Rheumatic Diseases: A Nationwide Population-Based Dynamic Cohort Study in Taiwan. Medicine. 2016;95(18):e3540.

29. Rezaieyazdi Z, Tabaei S, Ravanshad Y, Akhtari J, Mehrad-Majd H. No association between the risk of breast cancer and systemic lupus erythematosus: evidence from a meta-analysis. Clinical rheumatology. 2018;37(6):1511-9.

30. Tallbacka KR, Pettersson T, Pukkala E. Increased incidence of cancer in systemic lupus erythematosus: a Finnish cohort study with more than 25 years of follow-up. Scandinavian journal of rheumatology. 2018:1-4.

31. Ott G, Rosenwald A. Molecular pathogenesis of follicular lymphoma. Haematologica. 2008;93(12):1773-6.

32. Yurkovich M, Vostretsova K, Chen W, Avina-Zubieta JA. Overall and cause-specific mortality in patients with systemic lupus erythematosus: a meta-analysis of observational studies. Arthritis care \& research. 2014;66(4):608-16.

This article is protected by copyright. All rights reserved 
33. Bernatsky S, Ramsey-Goldman R, Petri M, Urowitz MB, Gladman DD, Fortin PF, et al. Breast cancer in systemic lupus. Lupus. 2017;26(3):311-5.

34. Bernatsky S, Ramsey-Goldman R, Joseph L, Boivin JF, Costenbader KH, Urowitz MB, et al. Lymphoma risk in systemic lupus: effects of disease activity versus treatment. Annals of the rheumatic diseases. 2014;73(1):138-42.

35. Hicks BM, Filion KB, Yin H, Sakr L, Udell JA, Azoulay L. Angiotensin converting enzyme inhibitors and risk of lung cancer: population based cohort study. BMJ (Clinical research ed). 2018;363:k4209.

36. Shen J, Huang YM, Wang M, Hong XZ, Song XN, Zou X, et al. Renin-angiotensin system blockade for the risk of cancer and death. Journal of the renin-angiotensin-aldosterone system : JRAAS. 2016;17(3). 


\begin{tabular}{|c|c|c|c|c|}
\hline \multirow[t]{2}{*}{ Variables } & \multirow{2}{*}{$\begin{array}{c}\text { All } \\
(n=3,539)\end{array}$} & \multicolumn{2}{|c|}{ Cancer } & \multirow{2}{*}{$\begin{array}{c}\mathrm{p}- \\
\text { value }\end{array}$} \\
\hline & & YES $(n=154)$ & NO $(n=3,385)$ & \\
\hline Female, n (\%) & $3,194(90.4)$ & $140(90.9)$ & $3,054(90.4)$ & 0.821 \\
\hline Age at first SLE criterion (years), mean (SD) & $32.84(14.4)$ & $38.35(16.0)$ & $32.72(14.3)$ & $<0.001$ \\
\hline Age at SLE diagnosis (years), mean (SD) & $34.85(14.5)$ & $40.37(15.7)$ & $34.75(14.5)$ & $<0.001$ \\
\hline Age at last assessment (years), mean (SD) & $46.52(14.8)$ & $57.74(14.4)$ & $46.17(14.6)$ & $<0.001$ \\
\hline \multicolumn{5}{|l|}{ Race, n (\%) } \\
\hline Caucasian & $3196(93.0)$ & $145(96.7)$ & $3051(92.8)$ & \\
\hline & & & & 0.071 \\
\hline Others & $241(7.0)$ & $5(2.7)$ & $236(7.2)$ & \\
\hline Period of disease evolution (months), mean (SD) & $142.86(100.6)$ & $208.71(103.0)$ & $140.1(99.7)$ & $<0.001$ \\
\hline Follow-up time in rheumatology dept. (months), mean (SD) & $120(87.6)$ & 170. $1(90.8)$ & 118.12 (86.9) & $<0.001$ \\
\hline Sjögren Syndrome, n (\%) & $503(14.4)$ & $31(20.5)$ & $472(14.1)$ & 0.029 \\
\hline SLEDAI, median [p25-p75] & $2[0-4]$ & $1[0-3]$ & $2[0-4]$ & 0.026 \\
\hline KATZ Index, median [p25-p75] & $2[1-3]$ & $3[2-4]$ & $2[1-3]$ & 0.001 \\
\hline Modified SLICC/ACR DI*, median [p25-p75] & $1[0-2]$ & $1[0-3]$ & $0[0-1]$ & $<0.001$ \\
\hline Modified Charlson Index*, median [p25-p75] & $2[1-3]$ & $3[2-4]$ & $1[1-3]$ & $<0.001$ \\
\hline Anti-malaria treatment time (months), median [p25-p75] & $60[24-120]$ & $78[27-136]$ & $60[24-110]$ & 0.099 \\
\hline Smoking (past and current smokers), n (\%) & $1656(46.8)$ & $76(49.4)$ & $1580(46.7)$ & 0.515 \\
\hline Alcohol, n (\%) & $111(3.482)$ & $6(4.4)$ & $105(3.4)$ & 0.517 \\
\hline Statins, n (\%) & $165(5.1)$ & $15(10.7)$ & $150(4.9)$ & 0.002 \\
\hline ACE Inhibitors, $\mathrm{n}(\%)$ & $313(9.7)$ & $20(14.6)$ & $293(9.5)$ & 0.05 \\
\hline Acetylsalicylic acid, n (\%) & $1061(37.180)$ & $55(40.4)$ & 1006 (36.9) & 0.408 \\
\hline Immunosuppressants, n (\%) & $1939(57.2)$ & $80(53.3)$ & $1859(57.4)$ & 0.326 \\
\hline Immunosuppressants type & & & & \\
\hline Non immunosuppressants, n (\%) & $2133(60.3)$ & $98(63.7)$ & $2035(60.1)$ & \\
\hline Cyclophosphamide/Mycophenolate/Mycophenolic, n (\%) & $973(27.59$ & $38(24.7)$ & $935(27.6)$ & 0.668 \\
\hline Methotrexate/Leflunomide, n (\%) & $433(12.3)$ & $18(11.7)$ & $415(12.3)$ & \\
\hline Oral contraception, $\mathrm{n}(\%)$ & $655(26.89$ & $25(23.6)$ & $630(27.0)$ & 0.437 \\
\hline
\end{tabular}




\begin{tabular}{lcccc}
\hline Corticoids at maximum doses, occasionally, $\mathrm{n}(\%)$ & $776(27.4)$ & $36(27.1)$ & $740(27.4)$ & 0.93 \\
Hospitalization per activity, $\mathrm{n}(\%)$ & $1902(54.6)$ & $88(57.9)$ & $1814(54.5)$ & 0.41 \\
№ of hospitalizations per activity, median [p25-p75] & $2[1-3]$ & $2[1-3]$ & $2[1-4]$ & 0.01 \\
Refractoriness, $\mathrm{n}(\%)$ & $873(24.6)$ & $39(25.3)$ & $834(24.6)$ & 0.847
\end{tabular}

SD: Standard Deviation; SLE: Systemic Lupus Erythematosus; SLEDAI: Systemic Lupus Erythematosus Disease Activity Index; SLICC/ACR DI: Systemic Lupus International Collaborative Clinics/American College of Rheumatology Damage Index; ACE Inhibitors: angiotensin-converting enzyme inhibitors; ${ }^{*}$ The score corresponding to cancer was excluded when calculating the index.

Table 2. Characteristics of women with Systemic Lupus Erythematosus and cancer stratified per hormone-sensitivity

\begin{tabular}{|c|c|c|c|}
\hline \multirow[t]{2}{*}{ Variables } & \multicolumn{2}{|c|}{ Hormone-sensitive Cancer } & \multirow[t]{2}{*}{ p-value } \\
\hline & YES $(n=44)$ & NO $(n=96)$ & \\
\hline Age at first SLE criterion (years), mean (SD) & $39.1(15.6)$ & $37.65(16.18)$ & 0.582 \\
\hline Age at SLE diagnosis (years), mean (SD) & $41.9(14.4)$ & $39.58(16.07)$ & 0.497 \\
\hline Age at last evaluation (years), mean (SD) & $57.9(13.1)$ & $57.31(15.29)$ & 0.901 \\
\hline \multicolumn{4}{|l|}{ Race, n (\%) } \\
\hline Caucasian & $44(100)$ & $87(94.57)$ & \\
\hline Others & $0(0)$ & $5(5.43)$ & 0.107 \\
\hline Period of disease evolution (months), mean (SD) & $198.8(85.9)$ & $212.76(112.33)$ & 0.352 \\
\hline Follow-up time in rheumatology dept. (months), mean (SD) & $175.66(81.58)$ & $163.80(94.78)$ & 0.493 \\
\hline Sjögren Syndrome, n (\%) & $11(26.2)$ & $19(20)$ & 0.294 \\
\hline SLEDAl, median [p25-p75] & $0[0-2]$ & $2[0-4]$ & 0.268 \\
\hline KATZ Index, median [p25-p75] & $2[2-3]$ & $3[2-4]$ & 0.059 \\
\hline Modified SLICC/ACR DI*, median [p25-p75] & $1[0-2]$ & $1.5[1-3.5]$ & 0.011 \\
\hline Modified Charlson Index*, median [p25-p75] & $2[2-3]$ & $3[2-4.5]$ & 0.034 \\
\hline Anti-malaria treatment time (months), median [p25-p75] & $84[19-144]$ & $74.5[32-133.5]$ & 0.715 \\
\hline Smoking (past and current smokers), $\mathrm{n}(\%)$ & $22(60.0)$ & $44(45.83)$ & 0.78 \\
\hline Alcohol, n (\%) & $1(2.9)$ & $2(2.27)$ & 0.779 \\
\hline Statins, $\mathrm{n}(\%)$ & $2(5.4)$ & $8(8.89)$ & 0.425 \\
\hline ACE Inhibitors, n (\%) & $4(10.8)$ & $11(12.64)$ & 0.735 \\
\hline
\end{tabular}




\begin{tabular}{lccc}
\hline Acetylsalicylic acid, $\mathrm{n}(\%)$ & $15(38.5)$ & $33(39.29)$ & 0.836 \\
Immunosuppressants, n (\%) & $19(46.3)$ & $53(55.79)$ & 0.188 \\
Type of Immunosuppressants & & & \\
Non immunosuppressants, n (\%) & $31(70.5)$ & $59(61.46)$ \\
Cyclophosphamide/Mycophenolate/Mycophenolic, n (\%) & $8(18.2)$ & $25(26.04)$ & 0.314 \\
Methotrexate/Leflunomide, n (\%) & $5(11.4)$ & $12(12.5)$ & \\
Oral contraceptives, n (\%) & $9(32.1)$ & $16(23.19)$ & 0.307 \\
Corticoids at maximum doses, occasionally, n (\%) & $6(16.7)$ & $24(28.92)$ & 0.163 \\
Hospitalization per activity, n (\%) & $21(50.0)$ & $57(59.38)$ & 0.382 \\
№ of hospitalizations per activity, median [p25-p75] & $2[1-3]$ & $2[1-3]$ & 0.257 \\
Refractoriness, $\mathrm{n}$ (\%) & $8(18.2)$ & $25(26.04)$ & 0.194
\end{tabular}

SD: Standard Deviation; SLE: Systemic Lupus Erythematosus; SLEDAI: Systemic Lupus Erythematosus Disease Activity Index; SLICC/ACR DI: Systemic Lupus International Collaborative Clinics/American College of Rheumatology Damage Index; ACE Inhibitors: angiotensin-converting-enzyme inhibitors; *The score corresponding to cancer was excluded when calculating the index. 
Table 3. Accumulated incidence of cancer in RELESSER patients and general population per the 2012 Cancer Registry of the National Institute of Statistics, stratified by age and gender

\begin{tabular}{|c|c|c|c|c|c|c|}
\hline \multirow[b]{2}{*}{ Age } & \multicolumn{3}{|c|}{ RELESSER $^{*}$} & \multicolumn{3}{|c|}{ GENERAL POPULATION $^{f}$} \\
\hline & Men & Women & Total & Men & Women & Total \\
\hline$<65$ years, $\mathrm{Al}(\mathrm{Cl} 95 \%)$ & $3.54(0.01-19.59)$ & $4.9(2.68-8.21)$ & $4.78(2.68-3.07)$ & $2.35(2.33-2.37)$ & $2.06(2.04-2.08)$ & $2.21(2.20-2.22)$ \\
\hline$\geq 65$ years, $\mathrm{Al}(\mathrm{Cl} 95 \%)$ & 14.10 (0.03-75.99) & $15.98(6.45-32.65)$ & $15.71(6.81-30.73)$ & 23.72(23.65-23.89) & 10.27(10.19-10.37) & $16.03(15.94-16.12)$ \\
\hline Total, Al (Cl 95\%) & $5.66(0.68-20.3)$ & 6.37 (3.95-9.73) & $6.31(4.00-9.45)$ & $5.56(5.53-5.59)$ & $3.67(3.64-3.69)$ & $4.60(4.58-4.62)$ \\
\hline
\end{tabular}

${ }^{*}$ Accumulated Incidence (Al) per 1000 patients; ${ }^{\circledR} \mathrm{Al}$ per 1000 inhabitants. 
Table 4. Standardized Incidence Ratio of cancer ( $n$ - cancer cases observed / $\mathrm{n}-$ of expected cancer cases) stratified by age and gender

\begin{tabular}{cccc}
\hline Age & Men & Women & Total \\
\hline$<65$ years, SIR (CI 95\%) & $1.51(0.62-2.40)$ & $2.38(1.84-2.91)$ & $2.16(1.71-2.61)$ \\
$\geq 65$ years, SIR (CI 95\%) & $0.59(0.0-1.26)$ & $1.55(1.15-1.95)$ & $0.98(0.73-1.23)$ \\
Total, SIR (CI 95\%) & $1.02(0.49-1.56)$ & $1.74(1.45-1.55)$ & $1.37(1.15-1.59)$ \\
\hline
\end{tabular}

SIR: Standardized Incidence Ratio. 
Table 5. Factors associated with hormone-sensitive cancers in women with Systemic Lupus Erythematosus

\begin{tabular}{|c|c|c|c|c|}
\hline \multirow[t]{2}{*}{ Variable } & \multirow{2}{*}{$\begin{array}{l}\text { Bivariant } \\
\text { OR (CI95\%) }\end{array}$} & \multicolumn{3}{|c|}{ Multivariant } \\
\hline & & p-value & OR (CI95\%) & p-value \\
\hline Age at first SLE criterion (years) & $1.03(1.01-1.05)$ & 0.001 & & \\
\hline Age at SLE diagnosis (years) & $1.03(1.01-1.05)$ & 0.001 & $1.04(1.01-1.07)$ & 0.002 \\
\hline Age at last evaluation (years) & $1.05(1.03-1.07)$ & $<0.001$ & & \\
\hline \multicolumn{5}{|l|}{ Race } \\
\hline \multicolumn{5}{|l|}{ Caucasian (reference) } \\
\hline \multicolumn{5}{|l|}{ Others } \\
\hline Period of disease evolution (months) & $1.00(1.00-1.01)$ & 0.001 & $1.01(1.00-1.01)$ & $<0.001$ \\
\hline Follow-up time in rheumatology dept. (months) & $1.01(1.00-1.01)$ & $<0.001$ & & \\
\hline Sjögren Syndrome & $1.94(0.98-3.94)$ & 0.057 & $1.60(0.72-3.53)$ & 0.246 \\
\hline SLEDAI & $0.89(0.78-1.01)$ & 0.063 & $0.94(0.82-1.08)$ & 0.394 \\
\hline KATZ Index & $0.96(0.80-1.16)$ & 0.707 & & \\
\hline Modified SLICC/ACR DI* & $1.11(0.95-1.29)$ & 0.188 & & \\
\hline Modified Charlson Index* & $1.27(1.10-1.46)$ & 0.001 & & \\
\hline Anti-malaria treatment time (months) & $1.00(1.00-1.00)$ & 0.818 & & \\
\hline Smoking (past and current smokers) & $1.25(0.69-2.26)$ & 0.464 & & \\
\hline Alcohol & $1.40(0.19-10.36)$ & 0.745 & & \\
\hline Statins & $1.07(0.26-4.50)$ & 0.925 & & \\
\hline ACE inhibitors & $1.22(0.43-3.48)$ & 0.706 & & \\
\hline Acetylsalicylic acid & $1.10(0.57-2.11)$ & 0.772 & & \\
\hline Immunosuppressants & $0.66(0.36-1.23)$ & 0.188 & & \\
\hline \multicolumn{5}{|l|}{ Type of Immunosuppressants } \\
\hline \multicolumn{5}{|l|}{ Non immunosuppressants (reference) } \\
\hline Cyclophosphamide & $0.60(0.27-1.30)$ & 0.194 & & \\
\hline /Mycophenolate/Mycophenolic, & & & & \\
\hline Methotrexate/Leflunomide & $0.78(0.30-2.03)$ & 0.618 & & \\
\hline Oral contraceptives & $1.10(0.50-2.45)$ & 0.813 & & \\
\hline
\end{tabular}


Hospitalization per activity

№ of hospitalizations per activity

Refractoriness

Anti-DNA

№ of pregnancies

Menopause
$0.89(0.48-1.63) \quad 0.699$

$1.01(0.86-1.19) \quad 0.887$

$0.72(0.33-1.55) \quad 0.394$

$0.69(0.37-1.30) \quad 0.249$

$0.88(0.40-1.92)$

0.75

$1.19(1.01-1.39) \quad 0.038$

$1.00(0.80-1.25)$

0.987

SLE: Systemic Lupus Erythematosus; SLEDAI: Systemic Lupus Erythematosus Disease Activity Index; SLICC/ACR DI: Systemic Lupus International Collaborative Clinics/American College of Rheumatology Damage Index; ACE Inhibitors: angiotensin converting-enzyme inhibitors; *The score corresponding to cancer was excluded when calculating the index. 
Table 6. Factors associated with non-Hormone-sensitive cancer in women with Systemic Lupus Erythematosus.

\begin{tabular}{|c|c|c|c|c|}
\hline \multirow[t]{2}{*}{ Variables } & \multicolumn{2}{|l|}{ Bivariant } & \multicolumn{2}{|l|}{ Multivariant } \\
\hline & OR (IC 95\%) & p-value & OR (IC 95\%) & p-value \\
\hline Age first criterion (years) & $1.03(1.01-1.04)$ & $<0.001$ & & \\
\hline Age at SLE diagnosis(years) & $1.02(1.01-1.04)$ & $<0.001$ & $1.04(1.01-1.07)$ & 0.019 \\
\hline Age at last evaluation (years) & $1.05(1.03-1.07)$ & $<0.001$ & & \\
\hline \multicolumn{5}{|l|}{ Race } \\
\hline Caucasian (reference) & & 0.478 & & \\
\hline Others & $0.72(0.29-1.79)$ & & & \\
\hline Period of disease evolution (months) & $1.01(1.00-1.01)$ & $<0.001$ & $1.01(1.00-1.01)$ & 0.029 \\
\hline Follow-up time in rheumatology dept. (months) & $1.01(1.00-1.01)$ & $<0.001$ & & \\
\hline Sjögren Syndrome & $1.39(0.83-2.31)$ & 0.213 & $0.95(0.35-2.57)$ & 0.246 \\
\hline SLEDAI & $0.96(0.90-1.02)$ & 0.209 & $0.97(0.86-1.09)$ & 0.394 \\
\hline KATZ Index & $1.16(1.05-1.29)$ & 0.005 & & \\
\hline Modified SLICC/ACR DI * & $1.32(1.21-1.43)$ & $<0.001$ & $1.27(1.04-1.57)$ & 0.022 \\
\hline Modified Charlson Index* & $1.43(1.31-1.56)$ & $<0.001$ & & \\
\hline Anti-malaria treatment time (months) & $1.00(1.00-1.00)$ & 0.264 & $1.00(1.00-1.00)$ & 0.947 \\
\hline Smoking (past and current smokers) & $1.06(0.70-1.59)$ & 0.791 & & \\
\hline Alcohol & $1.10(0.27-4.59)$ & 0.893 & & \\
\hline Statins & $1.83(0.87-3.86)$ & 0.112 & $0.33(0.04-3.04)$ & 0.329 \\
\hline ACE inhibitors ${ }^{\S}$ & $1.46(0.77-2.78)$ & 0.25 & $2.87(1.01-8.14)$ & 0.048 \\
\hline Acetylsalicylic acid & $1.14(0.73-1.78)$ & 0.565 & & \\
\hline Immunosuppressants & $0.96(0.64-1.46)$ & 0.864 & & \\
\hline Type of Immunosuppressants & & & & \\
\hline Non immunosuppressants (reference) & & & & \\
\hline Cyclophosphamide & $0.98(0.61-1.57)$ & 0.929 & & \\
\hline /Mycophenolate/Mycophenolic, & & & & \\
\hline Methotrexate/Leflunomide & $0.99(0.53-1.86)$ & 0.975 & & \\
\hline Oral contraceptives & $0.70(0.40-1.24)$ & 0.221 & $1.20(0.47-3.06)$ & 0.704 \\
\hline
\end{tabular}


SLE: Systemic Lupus Erythematosus; SLEDAI: Systemic Lupus Erythematosus Disease Activity Index; SLICC/ACR DI: Systemic Lupus International Collaborative Clinics/American College of Rheumatology Damage Index; ACE Inhibitors: angiotensin converting-enzyme inhibitors; ${ }^{*}$ The score corresponding to cancer was excluded when calculating the index. §Cancer patients prescribed ACE Inhibitors were more commonly hypertensive than those not prescribed these $(75 \%$ vs. $41 \%, p=0.005)$; furthermore, they were more frequently diagnosed with lupus nephritis ( $85 \%$ vs. $18.8 \%, p<0.001$ ). 